\title{
LINGUAGEM E SOCIEDADE: CRENÇAS E ATITUDES LINGUÍS- TICAS DOS ALUNOS DO ENSINO MÉDIO DE UMA ESCOLA PÚBLICA NO INTERIOR DA AMAZÔNIA
}

LANGUAGE AND SOCIETY: BELIEFS AND LINGUISTIC ATTITUDES OF STUDENTS OF HIGH SCHOOL OFA PUBLIC SCHOOL IN THE AMAZON

Manuel Benjamin Liberal', Heliud Luis Maia Moura²

Ronilson dos Santos Bezerra ${ }^{3}$, Rosangela Heloise Silva Monteiro ${ }^{4}$

RECEBIDO: 10/08/2017| 16/03/2018

DOI: $10.5902 / 2317175828559$

\section{RESUMO}

O presente trabalho buscou verificar as crenças e atitudes linguísticas dos alunos do ensino médio (primeiro, segundo e terceiro ano) do ensino médio da Escola Estadual Felisbelo Jaguar Sussuarana, na cidade de Santarém/Pa. Para tanto, foram analisadas as respostas fornecidas pelos alunos a seis questões metalinguísticas, presentes no Questionário do Atlas Linguístico do Brasil (COMITÊ NACIONAL DO ALiB, 2001). O corpus é composto por dados obtidos com 60 alunos/informantes entre 15 e 19 anos de idade. Verificou-se que a maioria dos informantes reconhece as diferenças de falares entre os moradores da cidade de Santarém e demais localidades.

Palavras-chave: Variação linguística; Crenças e atitudes linguísticas; Ensino; ALiB.

\footnotetext{
1Mestre em Letras pela Universidade Federal do Oeste do Pará - UFOPA. Secretário Executivo / UFOPA. Professor de Ensino fundamental e Médio da Rede Pública de Ensino - SEDUC/PA;

2Doutor em Linguística pela Universidade Estadual de Campinas - UNICÁMP. Professor Adjunto II da Universidade Federal do Oeste do Pará - UFOPA;

3Bacharel em Ciência da Computação pela Universidade Federal do Oeste do Pará - UFOPA. Técnico Administrativo em Educação - UFOPA;

4Especialização em Psicologia Éducacional com Ênfase em Psicopedagogia Preventiva pela Universidade Estadual do Pará - UÉPA. Subtenente vinculada à Seção de Planejamento, Ensino e Instrução - P - 3. $3^{\circ}$ BPM Batalhão Tapajós/Pa.
} 


\begin{abstract}
The present work aimed to verify the beliefs and linguistic attitudes of high school students (first, second and third year) of the State School Felisbelo Jaguar Sussuarana, in the city of Santarém I Pa. For that, the answers given by the students to the six metalinguistic questions present in the Brazilian Linguistic Atlas Questionnaire (ALiB NATIONAL COMMITTEE, 2001) were analyzed. The corpus consists of data obtained from 60 students / informants between 15 and 19 years of age. It was verified that the majority of the informants recognize the differences of speech between the residents of the city of Santarém and other localities.
\end{abstract}

Keywords: Linguistic variation; Beliefs and linguistic attitudes; Teaching; ALiB.

\title{
1 Introdução
}

Ainda nos dias de hoje, grande parte das aulas de língua portuguesa é dispensada, unicamente, ao ensino de regras gramaticais e a atividades de pouca relevância para o desenvolvimento da competência comunicativa do discente. Antunes $(2003,2010)$ entre outros (VIEIRA e BRANDÃO, 2014; TRAVAGLIA, 2009, 2013; NEVES, 2002) pontuam que, na maioria dos casos, o ensino tradicional da gramática continua mantido como o foco, sendo privilegiados de forma insistente nas aulas de português os fenômenos da língua, as nomenclaturas e as classificações das unidades, muitas vezes com o fim em si mesmas.

Essa forma de ensino pouco proporciona ao aluno pensar sobre a língua, o que acaba direcionado esse discente a entender que as aulas de língua portuguesa encerram-se na transmissão metalinguística de conceitos sobre a língua.

Estudar sobre variação linguística, é uma entre várias possibilidades de conduzir o aluno a refletir sobre sua língua. Isso porque, quase todo mundo parece ter pontos de vista definidos sobre a linguagem, sobre seu modo próprio de falar e sobre o modo como as outras pessoas falam. Esses pontos de vista, baseados em crenças particulares, podem direcionar o usuário da língua à realização de julgamentos e à tomada de atitudes frente à forma como o outro se posiciona linguisticamente, o que torna patente que o falar e o ouvir são frequentemente postos em avaliação.

Mesmo que o pensar sobre esse julgamento não esteja presente na "ordem do dia" das aulas de língua portuguesa, ele, já há muito tempo, encontra guarida em pesquisas de ordem social. Devido à importância do tema, diversos autores já se dedicaram ao estudo de crenças e atitudes linguísticas, cujas primeiras investigações remontam à década de 60, "quando Lambert et al. (1960) investigaram a avaliação de jovens canadenses falantes de francês e de inglês, em relação à sua própria língua" (CYRANKA, 2007, p. 26). Na década de 70, Labov (2008) também já apontava para a importância 
LINGUAGEM E SOCIEDADE: CRENÇAS E ATITUDES LINGUÍSTICAS DOS ALUNOS DO ENSINO MÉDIO DE UMA ESCOLA PÚBLICA NO INTERIOR DA AMAZÔNIA

de pesquisas nessa direção ao estudar a variação linguística, especificamente a fonética utilizada no inglês, na ilha de Martha's Vineyard.

Nesse sentido, ao aproximar o aluno de ensino médio ou qualquer outro indivíduo ao conhecimento das discussões referentes a essa temática pode significar contribuir para a formação de interactantes culturalmente sensíveis ao seu próprio falar e ao falar do outro, isso porque dialogar sobre crenças e atitudes linguísticas representa refletir sobre sua própria prática discursiva. De acordo com Pajares (1992), o termo crença pode ser definido como um entendimento pessoal de verdade ou de falsidade que um indivíduo faz sobre uma determinada proposição. Segundo esse autor, as crenças podem ser inferidas a partir do que as pessoas dizem ou fazem.

Por seu turno, Dewey (1933, p. 6 apud BARCELOS, 2010) destaca o caráter social e contextual das crenças, identificando-as como:

[...] uma forma de pensamento, como construções da realidade, maneiras de ver e perceber o mundo e seus fenômenos, coconstruídas em nossas experiências e resultantes de um processo interativo de interpretação e re(significação). Como tal, crenças são sociais (mas também individuais), dinâmicas, contextuais e paradoxais. (Barcelos, 2010, p. 18)

Assim, pode-se entender que as crenças estão relacionadas às construções e reconstruções de experiências, sendo socialmente estabelecidas na interação e na relação com os grupos sociais a que se faz parte, nesse caso, podendo atingir diretamente ao modo como o falante utiliza a linguagem.

De acordo com Silva e Aguilera (2014), essa relação entre linguagem e sociedade pode causar, nos usuários da língua, atitudes de rejeição ou de aceitação frente à língua ou à variedade linguística, isso porque, os indivíduos desencadeiam posicionamentos movidos por crenças incorporadas em sociedade, podendo apresentar no uso da língua manifestações de preconceito, de prestígio, discriminação, pertencimento, valorização ou estigmatização.

Por seu turno, Cyranka (2007), destaca que o estudo das atitudes linguísticas está relacionado ao da avaliação linguística, ou seja, ao valor que é atribuído aos julgamentos dos falantes em relação à língua ou ao dialeto utilizado por seu interlocutor.

Nesse sentido, pode-se entender, então, que as atitudes linguísticas são um constructo que podem explicar comportamentos em particular. Elas podem ser positivas ou negativas, "favoráveis" ou "desfavoráveis" de acordo com o sentimento que um falante tem em relação a sua própria variedade linguística e em relação à variedade linguística dos outros.

Por fim, Santos (1996, p. 8, apud CYRANKA, 2007, p. 22), em seu trabalho sobre atitudes e crenças escolares relativas ao ensino de português na escola, apresenta as seguintes definições sobre esses temas: 
Crença seria uma convicção íntima, uma opinião que se adota com fé e certeza.

[...] Já atitude seria uma disposição, propósito ou manifestação de intenção ou propósito. Tomando atitude como manifestação, expressão de opinião ou sentimento, chega-se à conclusão de que nossas reações frente a determinadas pessoas, a determinadas situações, a determinadas coisas seriam atitudes que manifestariam nossas convicções íntimas.

Nesse sentido, o que os professores de língua portuguesa precisam ter bem claro é que suas crenças e atitudes linguísticas podem influenciar a forma como lidam com os alunos e com o ensino de língua.

\section{Metodologia}

Esta pesquisa buscou investigar as crenças e atitudes linguísticas dos alunos do ensino médio $\left(1^{\circ}, 2^{\circ}\right.$ e $3^{\circ}$ ano) da escola pública estadual Felisbelo Jaguar Sussuarana, a respeito de sua língua materna. Para isso, foram utilizadas como instrumentos de análises as Perguntas Metalinguísticas (PM), que compõem parte dos questionários apresentados no Projeto Atlas Linguísticos do Brasil - AliB (COMITÊ NACIONAL, 2001).

De acordo com Cardoso \& Mota (2012), o Projeto ALiB representa a primeira tentativa em descrever o português brasileiro em nível nacional, tomando como base dados coletados in loco em várias localidades do país, por meio dos questionários expostos no projeto. Para os autores, o Projeto ALiB "se desenvolve no campo da variação linguística, mais especificamente no campo da Dialetologia e com base na Geolinguística, caminho metodológico que se ocupa da cartografia dos fatos de língua" (CARDOSO \& MOTA, 2012, p. 855).

De modo geral, os questionários apresentados pelo Projeto AliB, podem ser assim classificados: Questionário Fonético Fonológico (QFF), o Questionário Semântico-Lexical (QSL), o Questionário Morfossintático (QMS), as Questões de Pragmática (QP), as Perguntas Metalinguísticas (PM), os temas para discurso semidirigido (TDS) e um texto para leitura. Cada questionário apresenta objetivos específicos, nos quais se buscam obter:

no QFF, o registro de uma variante fônica em vocábulos selecionados; no QSL, variantes lexicais características da localidade, a partir do fornecimento dos semas pertinentes; no QMS, variantes morfossintáticas, em questões diretamente dirigidas ao fato ou passíveis de serem flagradas na descrição de uma gravura ou no relato feito pelo informante. As quatro questões de pragmática procuram saber como um rapaz jovem, ao encontrar um objeto na rua, se dirige a outro jovem, do sexo masculino e do sexo feminino, ou a um indivíduo idoso, também dos dois sexos, para dizer-lhe que o objeto caiu de seu bolso. As seis questões metalinguísticas indagam sobre o modo de falar local, as pes- 
soas que, segundo o informante, "falam de modo diferente" na localidade e em outras áreas brasileiras, o falar de épocas anteriores, solicitando exemplos dessas variantes. (CARDOSO \& MOTA, 2012, p.862).

Por questões inerentes ao objetivo desta pesquisa em investigar as crenças e atitudes linguísticas dos alunos, foram analisados apenas os registros obtidos por meio das perguntas Metalinguísticas (PM), AliB (COMITÊ NACIONAL, 2001, p. 46), que são: 1. Como se chama a língua que você fala?; 2) Tem gente que fala diferente aqui em Santarém? Se houver identifique os grupos que "falam diferente"; 3. Poderia dar um exemplo do modo como falam essas pessoas "que falam diferente"?; 4. E, em outros lugares do Brasil, fala-se diferente daqui de Santarém?; 5. Poderia dar um exemplo do modo como falam em outros lugares do Brasil?; e, 6. No passado, falavam diferente aqui?

O corpus constituiu-se das respostas fornecidas pelos alunos as seis perguntas. Para coletar os dados, o pesquisador apresentou aos alunos entrevistados um questionário impresso semi-estruturado, (com as seis perguntas padronizadas do referido Atlas Linguístico), para ser respondido por cada aluno, sendo posteriormente encaminhado ao pesquisador.

A coleta de dados foi realizada na própria escola, realizada na turma específica do aluno. Cada turma dispôs de duas horas para responder às questões. Foi tomado como universo de amostras o total 60 alunos/informantes, do $1^{\circ}, 2^{\circ}$ e $3^{\circ}$ ano, com faixa etária entre 15 e 19 anos.

Destaca-se que a escola na qual foi realizada a pesquisa faz parte da rede estadual de ensino e localiza-se na região Oeste do Estado do Pará. Ela está situada no município de Santarém e atende a uma clientela composta, em sua grande maioria, por alunos da classe baixa, que moram em áreas distantes da escola, necessitando de transporte público para se deslocarem à instituição. A escola também atende alunos indígenas (dos quais a maioria está em fase inicial de aprendizagem da língua portuguesa).

\section{Resultados}

A primeira análise é referente à questão 1 . Como se chama a língua que você fala? Dentre as 60 respostas, 47 alunos responderam falar português/ língua portuguesa e 13 responderam falar "brasileiro(a). 


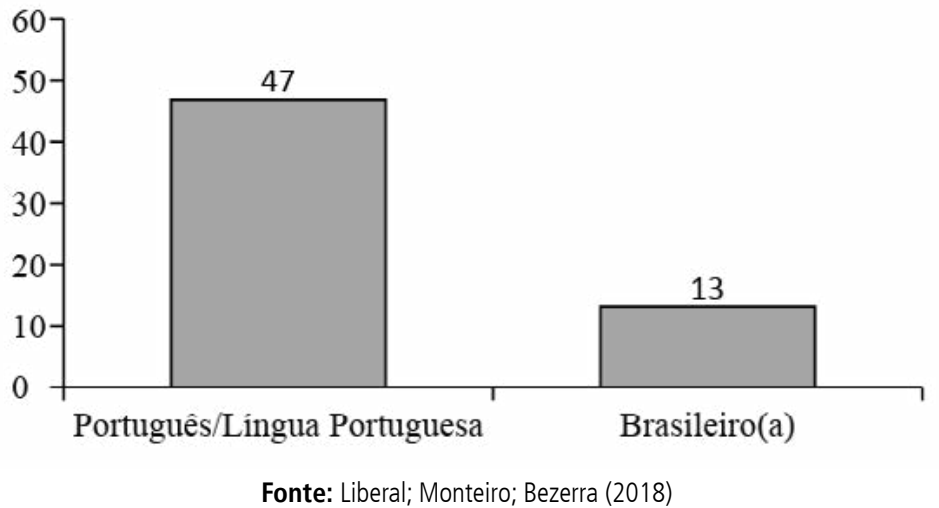

O Gráfico 1 apresenta o predomínio da resposta "Português/língua portuguesa", legitimando os conhecimentos vinculados à escola. Porém é possível perceber que alguns alunos, ao responderem "brasileiro(a)" parecem notar as diferenças existentes entre o português falado no Brasil e em Portugal.

O entendimento de língua como brasileira está vinculado à ideia de independência da nação. Quando os informantes denominam a língua que falam somente de "Português/língua portuguesa", pode-se reafirmar que no Brasil se fala uma única língua.

Porém, como bem explica Broch (2014), o Brasil é um país plurilíngue, mas a política linguística de estado se manifesta em diminuir o número de línguas, substituindo-as pela Língua Portuguesa, o que confirma os pressupostos de Oliveira (2009) sobre refreamento do plurilinguismo no Brasil, que o autor chama de "processo de glotocídio".

A permanência desse pensamento de que o Brasil só possui uma única língua pode ser resultado da exclusão de grupos étnicos e linguísticos, por isso, o uso do nome "Português" não pode ser visto como resposta óbvia ou como resposta única.

Por meio da próxima pergunta, questão 2 . Tem gente que fala diferente aqui em Santarém? Se houver identifique os grupos que "falam diferente", objetivou-se investigar o conhecimento dos informantes sobre a existência da variação linguística. Para buscar tal resposta, os alunos foram questionados a respeito da fala do outro. Pelas respostas obtidas, foi observado que os discentes possuem um prévio conhecimento sobre a variação linguística, havendo unanimidade em respostas positivas (os 60 alunos afirmaram ser possível identificar diferenças na fala dos habitantes de Santarém).

Foi solicitado que os informantes identificassem esses grupos que "falam diferente". Considerando que um mesmo discente apontou a existência de mais de um grupo diferente, as respostas obtidas foram organizadas em quatro categorias: 1) grupo outras cidades (presentes em 36 respostas - "falar carioca, falar manauara, falar gaúcho, falar nordestino"); 2) grupo indígena (presentes em 34 respostas); 3) grupo ribeirinhos/interior (presentes em 32 respostas) e 4) grupo estrangeiros (presentes em 12 respostas). 
LINGUAGEM E SOCIEDADE: CRENÇAS E ATITUDES LINGUÍSTICAS DOS ALUNOS DO ENSINO MÉDIO DE UMA ESCOLA PÚBLICA NO INTERIOR DA AMAZÔNIA

A pergunta seguinte solicitou que os alunos apresentassem exemplos sobre os modos como falam essas pessoas "que falam diferente": 3. Poderia dar um exemplo do modo como falam essas pessoas "que falam diferente"? Dos 60 entrevistados, 39 alunos fizeram referência à fala do morador do interior/sítio/ribeirinho e 28, dentre os 60 entrevistados fizeram referência à fala do indígena. Alguns alunos exemplificaram falas para os dois grupos anteriormente mencionados (morador do interior/sítio/ribeirinho, indígena). Seguem abaixo alguns exemplos dos relatos dos alunos:

Tem palavras que são diferentes..., aqui em Santarém chamam acari', em Manaus é bodó (aluno 48).

a gente fala macaxeira, os indígena falam cupim (aluno 24).

Nós falamos muito "olha já"2, enquanto que outras pessoas dizem "marmenino", (aluno 15).

Nas três frases acima, os alunos fazem menção às diferenças lexicais, no entanto, não imprimem juízos de valor em seus relatos. Nas frases abaixo, os discentes identificam e avaliam casos de variação fonética entre o falar santareno e o falar amazonense, bem como a presença do sotaque presente no falar "não local": "tem um pessoal que vem de Manaus que puxa o 's' no final das palavras (aluno 38)", "as pessoas que vem do nordeste e do sul falam um pouco estranho (aluno 2 )".

Essa atitude linguística reforça o mito do "não sotaque" na fala dos naturais da localidade, ou seja, "apenas pessoas de outra localidade possuem sotaque". As frases seguintes demonstram flagrantes avaliações negativas sobre o uso da língua:

A gente ouve umas palavras erradas: "canua, buto," (aluno 19). os caboclos falam cumpadi para compadre e canua para conoa (aluno 3).

pessoas que moram no sítio falam bem diferente das pessoas que moram na cidade, já morei no sítio por isso sei. Por exemplo 'boto', lá (no sítio) eles falam buto. (aluno 6).

Os indígenas falam "eu gostá de você". É difícil de entender (aluno 44). Os indígenas falam um pouco demorado, os ribeirinhos trocam o 'o' pelo 'u' (aluno 37).

As pessoas do interior falam meio errado, tipo: canua, pobrema (aluno 19).

Os indígenas falam demorado, parece que falam um pouco forte algumas palavras (aluno 53)

De modo geral, os alunos apontaram as diferenças/ "erros" no modo como o indígena ou o morador do interior falam, partir do seu próprio modo de falar, ou seja, os alunos tomaram como base para avaliar essa pessoas, o seu próprio conhecimento linguístico.

Quando os informantes avaliam quem fala melhor, estão expressando sua atitude, como pode ser observado, ao considerarem melhores falantes "os

\footnotetext{
10 aluno se refere a um nome de peixe.

2 Expressão idiomática que está relacionada a espanto, surpresa, admiração.
} 
da cidade" em detrimento aos falantes "do sítio/indígena", estão apresentando uma atitude valorativa carregada de preconceito linguístico, "a ideia segundo a qual há modos de bem falar a língua e outros que, em comparação, são condenáveis" (CALVET, 2004, p. 68).

Esse preconceito, observado nas análises, parte, na realidade, do modo como os informantes avaliam socialmente o falante ribeirinho/interior e o falante indígena. Sobre o assunto, Alkmim (2007, p.42) assegura que:

[...] os julgamentos sociais ante a língua - ou melhor as atitudes sociais - se baseiam em critérios não linguísticos: são julgamentos de natureza política e social. Não casual, portanto, que se julgue feia a variedade dos falantes de origem rural, de classe baixa, com pouca escolaridade, de regiões culturalmente desvalorizadas.

Quanto às questões "4. E, em outros lugares do Brasil, fala-se diferente daqui de Santarém?" e "5. Poderia dar um exemplo do modo como falam em outros lugares do Brasil?" são apresentadas diferenças em relação aos falantes provenientes de outras localidades brasileiras, sendo mencionadas grandes cidades como: Manaus em 26 respostas, São Paulo em 21 respostas, Rio de Janeiro em 14 respostas, Rio Grande do Sul em 8 respostas, Bahia em 6 respostas, Minas Gerais em 2 respostas, e, Curitiba em 1 resposta. Não houve, porém, exemplificações para nenhuma resposta. Ressalta-se que ocorreram casos nos quais um mesmo aluno apontou mais de uma localidade com falar diferente. Segue quadro identificando número de respostas que apontaram diferenças no falar entre naturais de Santarém e de grandes cidades:

\begin{tabular}{|l|l|}
\hline Manaus & 26 respostas \\
\hline São Paulo & 21 respostas \\
\hline Rio de Janeiro & 14 respostas \\
\hline Rio Grande do Sul & 8 respostas \\
\hline Bahia & 6 respostas \\
\hline Minas Gerais & 2 respostas \\
\hline Curitiba & 1 resposta \\
\hline
\end{tabular}

Para mais bem apresentar as respostas obtidas à quarta questão, foi elaborado o seguinte gráfico: 
LINGUAGEM E SOCIEDADE: CRENÇAS E ATITUDES LINGUÍSTICAS DOS ALUNOS DO ENSINO MÉDIO DE UMA ESCOLA PÚBLICA NO INTERIOR DA AMAZÔNIA

Gráfico 2 - 4. E, em outros lugares do Brasil, fala-se diferente daqui de Santarém?

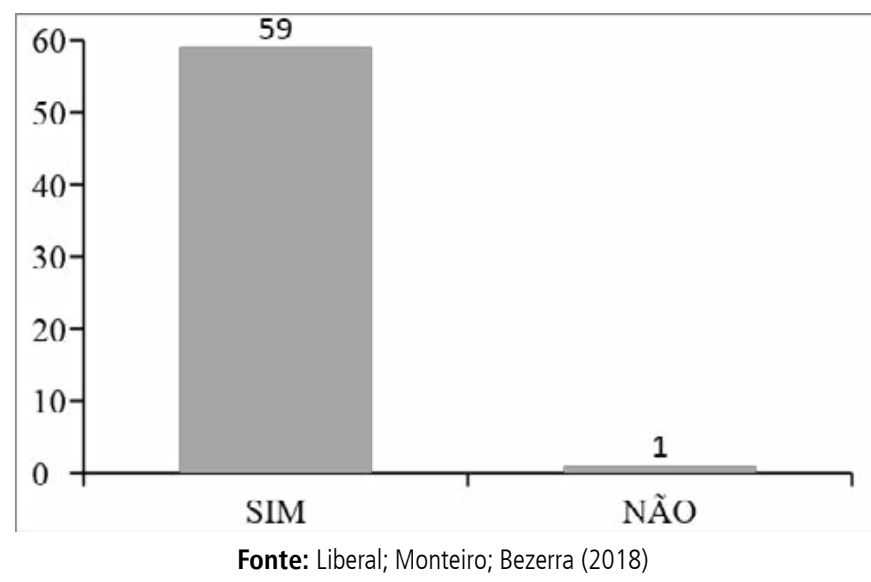

De acordo com o Gráfico 2, 59 alunos reconhecem que há diferença no modo como os falantes de outros lugares do Brasil se comunicam. Para exemplificar as respostas dadas a essa questão toma-se os relatos dos alunos 28 e 44, respectivamente: "Sim, porque cada lugar tem seu sutaque ou modo de falar", "Sim, porque cada capital tem um sutaque diferente".

Além dessas respostas, julgo interessante ressaltar que 1 aluno alegou que em outros lugares, não se fala diferente de Santarém, ou seja, para esse discente, em todo os demais locais do Brasil é falado da mesma maneira. $\mathrm{Na}$ fala do aluno 2: "Não, só o sotaque que muda".

Mesmo respondendo que não se fala diferente em outras localidades do Brasil, o aluno é capaz de identificar que existe uma forma própria de falar em diferentes regiões, manifestada por meio do sotaque. Provavelmente, esse aluno possui a crença que em todo território brasileiro se fala uma única língua, o "português".

Como última pergunta analisada: "6. No passado, falavam diferente aqui?" foi possível coletar os seguintes resultados, demonstrados por meio do gráfico 3 :

Gráfico 3 - 6. No passado, falavam diferente aqui?

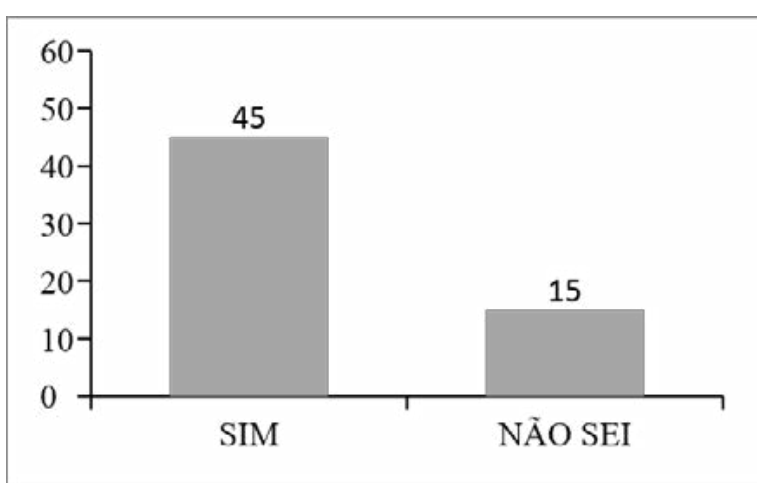

Fonte: Liberal; Monteiro; Bezerra (2018) 
Dos 60 alunos entrevistados, 45 informaram que no passado, se falava diferente. Do total de alunos, 15 informaram não saber responder tal pergunta. Nenhum aluno respondeu "não". Em relação aos 15 alunos que responderam "não sei", é possível inferir que tal resposta se deu devido a pouca idade dos informantes (de 15 a 19 anos) o que os the confeririam pouca experiência (cronológica) de vida para responder essa questão, provavelmente poderiam ser obtidas outras respostas caso fossem questionados informantes mais velhos.

Por outro lado, dos 45 alunos que informaram "ser falado de forma diferente no passado", 14 lançaram mão de um provável conhecimento histórico para responder essa questão, pois alegaram que se falava diferente pelo fato de serem os índios os antigos habitantes deste lugar: "Só os índios existiam antigamente (aluno 2)", "Sim, porque no passado as pessoas que habitavam aqui eram os índios e eu acredito que eles não falavam igual a nós (aluno 13)", "Eu acredito que sim, porque era os índios (aluno 58)", "Sim, aqui falavam a língua indígena (aluno 36)", "Acho que sim, porque quem vivia aqui antes de nós foram os índios e ele falavam tupi ou outras línguas (aluno 34)", "Sim, porque tinha os índios e eles não falavam a nossa língua (aluno 15)".

Foram, ainda, coletadas respostas com afirmativas que evidenciam o uso da língua por "gerações diferentes": "Sim, devido em outro tempo se falar diferente do atual (aluno 52)", "Sim, hoje se fala com gírias diferentes das do passado (aluno 42)".

Esses relatos reforçam que a idade dos informantes pode influenciar em suas crenças e respostas.

\section{Considerações finais}

Foram analisadas as respostas de 60 aluno/informantes, relativas às Perguntas Metalinguísticas (PM) constantes dos Questionários do Atlas Linguístico do Brasil - AliB, referentes à língua que cada um fala e sobre a existência ou não de grupos que falam diferente na localidade. Foi verificado que a maioria (47 alunos) acredita falar o português ou língua portuguesa, já a minoria (13 alunos) acredita falar brasileiro. Foi possível verificar também, a partir deste estudo, que os alunos apresentam crenças e atitudes semelhantes no que diz respeito às diferenças de falares. Isso pode ser resultado de haver um número pequeno de informantes, apenas 60 , o que representa dizer que esse resultado não pode ser generalizado.

Pode também ser concluído que a abordagem da variação da língua não se faz presente na sala de aula, o que revela a necessidade de maior proximidade entre as pesquisas sociolinguísticas desenvolvidas no meio acadêmico e o trabalho realizado no ambiente escolar.

Por fim, destaca-se a importância de refletir que, na maioria dos casos, quando se pensa a variação linguística pode ser difícil ter que admitir que preconceito se manifesta contra as pessoas, e não contra a língua, porém pelo fato da língua refletir o falante, é tendencioso achar que o preconceito é apenas linguístico. 
LINGUAGEM E SOCIEDADE: CRENÇAS E ATITUDES LINGUÍSTICAS DOS ALUNOS DO ENSINO MÉDIO DE UMA ESCOLA PÚBLICA NO INTERIOR DA AMAZÔNIA

Ao invés de condenar ou estereotipar as formas "diferentes" de falar, é necessário aprender a aceitar e a apreciar essas variedades, ou melhor, deve-se aprender a apreciar seus usuários.

\section{Referências}

ANTUNES, Irandé. Aula de português: encontro \& interação. São Paulo: Parábola Editorial, 2003.

Análise de textos: fundamentos e práticas. São Paulo: Parábola Editorial, 2010.

AGUILERA, V. A. Crenças e atitudes lingüísticas: o que dizem os falantes das capitais brasileiras. Estudos Linguísticos (São Paulo), v. 2, p. 105-112, 2008. Disponível em <http://www.gel.org.br/estudoslinguisticos/volumes/37/EL_V37N2_11.pdf>. Acesso em 10 jun. 2016.

ALKMIM, T. M. Sociolinguística: parte I. In: MUSSALIM, F.; BENTES, A. C. (Org.). Introdução à linguística: domínios e fronteiras. 6.ed. São Paulo: Cortez, 2007. p.21-48.

BARCELOS, A. M. F. Cognição de professores e alunos: tendências recentes na pesquisa de crenças sobre ensino e aprendizagem de línguas. In: BARCELOS, A. M. F., ABRAHÃO, M. H. V. (Orgs.). Crenças e ensino de línguas: Foco no professor, no aluno e na formação de professores. Campinas, Ed. Pontes, 2010, p.15-42.

$\mathrm{BROCH}$, Ingrid Kuchenbecker. Ações de promoção da pluralidade linguística em contextos escolares. Tese de doutorado. 265 f. Programa de Pós-Graduação em Letras. Universidade Federal do Rio Grande do Sul. Porto Alegre: UFRGS, 2014.

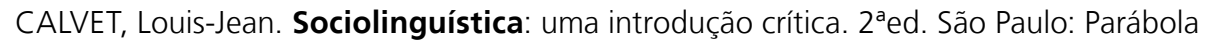
editorial, 2004.

CARDOSO, S. A.; MOTA, J. A. Projeto atlas linguístico do Brasil: antecedentes e estágio atual. Alfa, São Paulo, v.56, n.3, p.855-870, 2012. Disponível em: http://www. scielo.br/pdf/alfa/v56n3/a06v56n3.pdf. Acesso em 10 jun. 2016.

COMITÊ NACIONAL DO PROJETO ALiB (Brasil). Atlas linguístico do Brasil: questionário 2001. Londrina: Ed.UEL, 2001. Disponível em https://alib.ufba.br/sites/alib.ufba.br/ files/questionario_alib.pdf. Acesso em 10 jun. 2016.

CYRANKA, Lucia Furtado de Mendonça. Atitudes lingüísticas de alunos de escolas públicas de Juiz de Fora - MG. 2007. 174 f. Tese (Doutorado em Estudos Linguísticos)_Instituto de Letras, Universidade Federal Fluminense, Niterói, 2007.

LABOV, W. Padrões sociolinguísticos. São Paulo: Parábola, 2008. [AGUILERA, V. de A. Crenças e atitudes linguísticas: o que dizem os falantes das capitais brasileiras. Estudos Linguísticos, São Paulo, v.2, p.105-112, 2008.

LIBERAL, Manuel Benjamin. Práticas de produção textual: análise dos fatores de textualidade evidenciados nas produções textuais de alunos do $3^{\circ}$ ano do ensino médio de uma escola pública de Santarém. 2016. 114 f. Dissertação (Mestrado em Letras) - Universidade Federal do Oeste do Pará, Santarém, 2016.

NEVES, Maria Helena. A Gramática: história, teoria e análise, ensino. São Paulo: Editora Unesp, 2002.

OLIVEIRA, Gilvan M. Brasileiro fala português: Monolinguismo e Preconceito Linguístico. Linguasagem, v. 11, 2009. Disponível em < http://www.letras.ufscar.br/ linguasagem/edicao11/artigo12.pdf>. Acesso em 01 Jun. 2016.

PAJARES, M. F. Teachers' beliefs and educational research: cleaning up a messy construct. Review of educational research, 62/3, 307-332. 1992. Disponível em: < http://rer.sagepub.com/content/62/3/307>. Acesso em 01 Jun. 2016. 
MANUEL BENJAMIN LIBERAL, HELIUD LUIS MAIA MOURA RONILSON DOS SANTOS BEZERRA, ROSANGELA HELOISE SILVA MONTEIRO

SILVA, Hélen Cristina da; AGUILERA, Vanderci de Andrade. O poder de uma diferença: um estudo sobre crenças e atitudes linguísticas. Alfa, rev. linguíst. (São José Rio Preto), São Paulo, v. 58, n. 3, p. 703-723, 2014. Disponível em <http://www.scielo.br/ scielo.php?script=sci_arttext\&pid=\$198157942014000300703\&lng=en\&nrm=iso>. Acesso em 12 jun. 2016.

TRAVAGLIA, Luiz Carlos. Gramática e interação: uma proposta para o ensino de gramática. 14. ed. São Paulo: Cortez, 2009

. Na trilha da Gramática: conhecimento linguístico na alfabetização e letramento. São Paulo: Cortez, 2013.

VIEIRA, S. R; BRANDÃO, S. F. (Org). Ensino de Gramática: descrição e uso. $2^{a}$ ed. São Paulo: Contexto, 2014 